theology and twentieth-century thought toward important but frequently neglected sites for future exploration.

DAVID KATZ

University of Massachusetts, Amherst

Kyd, Thomas.

The Spanish Tragedy: Authoritative Text, Sources and Context, Criticism. Ed. Michael Neill.

A Norton Critical Edition. New York: W. W. Norton \& Company, 2014. Pp. xl, $289+5$ ill. ISBN 978-0-393-93400-7 (paperback) US\$13.12.

Michael Neill's edition of The Spanish Tragedy provides an opportunity to rethink the play's canonical significance and to appreciate the difficult choices facing editors who work with the space restrictions of print editions.

It's clear from Neill's introduction that he wants us to pay careful attention to the details of language, style, metre, and literary devices, and to note Kyd's "frequent uses of stichomythia" (xii) and plenty of "carefully balanced figures of antithesis and chiasmus" (xiv). Stylistic shifts, too, "mimic" Hieronimo's conflicted psyche. Neill speaks of Kyd's "ceremonious style" (xvi) being disrupted by-and sometimes mirroring-larger rhetorical and political shifts in action and plot. Thus, the play's minutiae are inextricably connected to its theme, which, says Neill, is "the administration of law [...] [that] was often haphazard and sometimes corrupt" (xxix).

For Neill, the play "established the set of conventions" defining the whole revenge tragedy subgenre (xxvii). The persistence of the play's many printings and stagings testifies to its rightful place in the early modern canon. The same sentiment was expressed earlier by J. R. Mulryne (Th. Kyd, The Spanish Tragedy, 1989, rpt. 2000), who was also enraptured by "the play's enormous and longlived popularity" (xxxiv). While I concur with Neill's and Mulryne's assessment, I wonder how many students (and academics) are drawn to the play more by the force of its ancestral affinity to Hamlet than by the attractiveness of its literary merits.

The Spanish Tragedy's problematic textual history emerges from discrepancies between Abel Jeffe's and Edward White's 1592 octavo-in-fours 
(Q1), and a subsequent 1602 edition printed by Thomas Pavier, containing four chunks (320 lines) of "added material" of uneven and sometimes questionable merit. The 1602 edition inserted "the Additions" in four discrete pieces and placed them variously after 2.5.45, 3.2.66, and 3.11.1, and between 3.12 and 3.13 (Neill calls Addition 4 "3.12A").

Both contending editions claim to offer improvements over predecessors. The undated Q1 title page reads, "[n]ewly corrected and amended of such grosse faults as passed in the first impression," thus tantalizingly intimating the existence of some earlier, lost version. Presumably, this authority is why Neill makes it his copy text. The 1602 title page says "The Spanish Tragedie containing the lamentable end of Don Horatio and Bel-imperia. Newly corrected, amended and enlarged with new additions of the Painters part, and others, as it hath of late been divers times acted."

Mulryne and Neill both use Q1 as a copy text, but Mulryne kept "the additions" separate, placing them at the end of the play. In contrast, Neill inserts the 1602 "additions" right into Q1. He also uses fresh, re-started throughline numbering for each of the four additions. He flags these additions with headings and a smaller font so they are visually distinguishable from Q1 (these are welcome features), but the duplication of line numbers now makes citation unnecessarily cumbersome. There are other options such as $2.5 .45+1,2.5 .45+2$, 2.5.45+3 (etc.) that might have been better.

Neill's claim that Q1 is "the only surviving text [...] with any claim to authority" (xxxix) is not consistent with his decision to embed the four additions into Q1 in their 1602 locations. Either Q1 is the "only" authoritative text, or it is not. And yet, I like the convenience of Neill's choices. The nuanced complexity of textual variants can never be easily represented on a printed page. Mulryne lamented the fact that "it is irritating to meet glosses one does not need, but it is infinitely more annoying to find an editor has assumed knowledge where none exists" (xxxvi). He was really talking about layout limitations of print. Digital editions can empower the reader to hide/reveal-even move-discrete pieces of text with ease. Print editors are not so blessed. Although Mulryne locates the four additions at the end and is more logical and consistent than Neill, the reader has to keep flipping back and forth to read them. Conversely, even though Neill is inconsistent by inserting the rejected 1602 into Q1, the convenience of having the four additions embedded in Q1 is greatly appreciated. Location is everything. 
Neill is transparent about editorial changes in orthography and punctuation, providing a list of "significant departures" ( $\mathrm{xl})$ at the end of the play. His editorial transparency is an improvement over Mulryne, who hides much of that. In the case of Neill's edition, I would have preferred to see textual variants on the page where they occur, below the text, but above the annotations/glosses. It's (mildly) annoying to have to keep flipping to the back of the play to see those textual variants. Of course, for readers who are not interested in textual criticism or editorial changes, it's just as irritating to see that information when you aren't interested in it. Hence the dilemma. Both editions provide excellent footnoted glosses and annotations, but Neill's are more extensive and robust, and therefore immensely helpful.

There are nine critical essays covering a range of topics, but Neill has brilliantly added a heading/tagline at the beginning of each essay that describes its topic. Anyone perusing the essays with a particular idea in mind will find these taglines wonderfully helpful. The edition also includes five greyscale illustrations, but only one (a woodcut of the title page of the 1615 edition showing Hieronimo finding Horatio's body) is directly related to the play. The others deal with more general themes of fortune, love, and garden motifs. The "Sources and Biography" section offers excerpts from some seminal (i.e., Virgil) and contemporary primary sources. Like the illustrations, these resources will be helpful to some readers, but hardly to all. Still, they are nice to have.

This thoughtful edition is well worth using and highly appropriate for use in any post-secondary educational context.

PETER PAOLUCCI

York University

\section{Lesser, Zachary.}

\section{Hamlet after Q1: An Uncanny History of the Shakespearean Text.}

Philadelphia: University of Pennsylvania Press, 2015. Pp. $292+27$ b/w ill. ISBN 978-0-8122-4661-2 (hardcover) US\$59.95.

When, in 1823, a copy of the hitherto unknown 1601 first quarto of Hamlet was discovered in the library of Sir William Bunbury, the history of that famous play was forever changed. Q1 was half the length of the better known quarto of 